\title{
Walter J. Ong: Vida e Obra
}

Julieta Oliveira

A morte de Walter J. Ong, no dia 12 de Agosto de 2003, aos 90 anos, motiva a presente abordagem ao pensamento e à actividade académica de um dos mais ilustres teóricos pós-modernos.

Professor na Universidade de Saint Louis, onde ensinou durante 36 anos, Ong estudou ao lado de Marshall McLuhan, aquando da sua tese de Mestrado em língua inglesa, da qual o próprio MacLuhan foi orientador. Aliás, este não deixou de citar Walter Ong no clássico A Galáxia de Gutenberg.

Durante a sua carreira académica, Walter Ong ensinou e foi orador nas mais prestigiadas instituições e viu os seus livros publicados em mais de 400 edições, em todo o mundo, e os seus ensinamentos citados em mais de dois mil

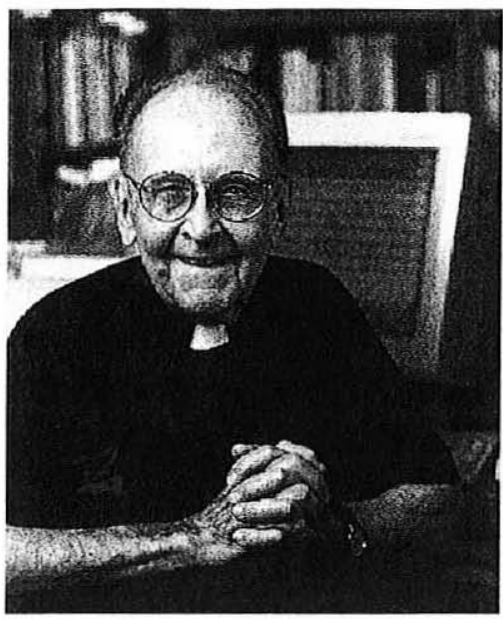
trabalhos.

Nascido em 1912, no Kansas, conquistou o seu primeiro diploma universitário, em língua latina, aos 16 anos. Em 1935 entrou para a Companhia de Jesus e 11 anos mais tarde foi ordenado padre católico. Licenciou-se posteriormente em filosofia e em teologia, antes de conquistar o doutoramento em língua inglesa, na Universidade de Harvard, em 1955.

Ainda hoje, as suas ideias são apropriadas por todos os tipos de profissionais e pensadores, desde psicólogos a feministas dos quatro cantos do globo. As suas conclusões foram usadas para analisar a competência oratória de Martin Luther King e para estudar os graffiti do metro de Nova Iorque. A acrescentar a uma vida de mérito, vários foram os governos que distinguiram o seu trabalho académico com prémios ou menções honrosas, como por exemplo a França, o Japão e a Nigéria.

Walter Ong colaborou com diversas instituições americanas, nomeadamente com o próprio governo. Em 1967, o presidente americano Lyndon B. Johnson convidou-o a assumir um cargo, na área da educação. Entre 1968 e 1974 participou como membro do Conselho Nacional de Humanidades. Em 1978 foi eleito presidente da Modern Language Association of America, a maior sociedade académica do mundo.

Entre as várias honras que recebeu, destacam-se a Espada de Ignatius Loyola, a maior honra concedida pela Universidade de Saint Louis, em 1993, e o Prémio "Lifetime Achievement”, em 1997, atribuído pela Conferência Americana de Cristianismo e Literatura.

Em 1982, Ong escreveu um dos livros que mais ajudam a compreender os mecanismos da cultura oral e da cultura escrita e as formas como estas influenciam os

\footnotetext{
* Mestranda de Ciências da Comunicaçào, Universidade do Minho.
} 
processos cognitivos humanos. Orality and Literacy: The Technologizing of the Word (Routledge, 1999) é um livro surpreendente porque aborda, de forma simples, aspectos da oralidade e da escrita sobre os quais raramente nos atemos, mas que todos usamos, neste dia-a-dia de cidadãos letrados da cultura ocidental.

Ong leva-nos à conclusão de que falar e escrever são actos de tal modo intrincados e vulgarizados, dentro de uma cultura letrada, que as mais das vezes não somos capazes de perceber que o acto de escrever e ser lido só é possivel porque a nossa oralidade está marcada de forma permanente por uma tecnologia que nos permite a compreensão dos textos. Essa tecnologia é a escrita. Este é um dos paradoxos que estabelece as relações entre a palavra originalmente falada e as suas transformações tecnológicas.

Segundo o autor, numa cultura oral, a restrição das palavras ao som determina, não apenas o nosso modo de expressão, mas também os processos de raciocínio. Numa cultura oral só conhecemos aquilo que somos capazes"de recordar. O pensamento está por isso associado à comunicação. São os interlocutores que verificam e validam o conhecimento de quem se expressa. O que quer dizer que, para elaborar e exprimir um discurso devidamente articulado, o orador tem que estabelecer o seu pensamento num registo memorizado, talhado de forma a poder recorrer ao mesmo rapidamente.

Numa cultura oral do tipo primário, os tipos de entendimento e expressão tendem a ser, segundo Ong, dos seguintes tipos: mais aditivo do que subordinativo; mais sintético do que analítico; redundante; conservador e tradicionalista; próximo dos mundos de vida; expresso num tom agonístico ou controverso e de forma a criar mais empatia e participação do que distância objectiva; desinteressado por definições, isto é, as palavras ganham sentido no aqui e agora da relação interpessoal; situacional em vez de abstracto.

Ong considera que a oralidade primária promove o desenvolvimento da estrutura da personalidade, tornando-a menos introspectiva do que é comum entre os letrados. Na cultura oral primária, onde a palavra tem a sua existência no som, sem qualquer referência a qualquer texto visual perceptível, o som entra profundamente no sentido existencial humano, processado pela palavra falada. O som é o sentido humano mais interiorizado, sendo, por isso, o principal responsável pela "psicodinâmica da oralidade".

Segundo Ong, a transposição crítica e única para novos mundos do conhecimento foi conquistada através de consciência humana, não apenas quando simples marcas semióticas foram produzidas, mas quando foi inventado um sistema codificado de marcas visíveis, que permite a quem escreve determinar as palavras que o leitor poderá retirar do texto.

O ser humano letrado não é mais do que um ser cujo pensamento se desenvolveu, não de forma natural, como se de poderes intrínsecos se tratasse, mas a partir de poderes estruturados por uma tecnologia completamente artificial, que transformou a consciência humana.

A escrita estabelece aquilo a que Ong chamou "discurso autónomo", isto é, o discurso que ganha ontologia própria.

Em contraste com o discurso oral natural, a escrita é na verdade completamente artificial. Escrever implica anos de prática e de dedicação, até que se consiga atingir 
uma certa performance, que só é conseguida a partir do momento em que esta tecnologia se torna numa segunda natureza e uma parte psicológica do seu utilizador. Tal e qual um músico, na sua relação com o instrumento musical, a aprendizagem tecnológica é, no entender de Walter Ong, desumana. Paradoxalmente, Ong considera que a artificialidade é natural ao ser humano e pode enriquecer a psique humana, alargar o espírito e intensificar a sua vida interior.

Ong considera que falar implementa a consciência da vida e faz-nos sair da inconsciência profunda, porque as regras gramaticais da oralidade situam-se a um nível inconsciente. Já o processo de passar da oralidade à escrita é governado por regras conscientes, explícitas e aprendidas.

A invenção da escrita foi e continua a ser, para Ong, o maior acontecimento de todas as invenções tecnológicas humanas. A escrita transformou o discurso e o pensamento, porque deslocou o discurso da sua natureza oral para um novo mundo sensitivo: o mundo visual.

A nossa compreensão acerca do desenvolvimento da escrita, nomeadamente quanto ao seu aparecimento tardio e quanto à sua base num único alfabeto, está relacionada quer com a sua arqueologia (que Ong se detém a desenvolver), quer com as próprias características evasivas do som, que só foram ultrapassadas a partir do momento em que este foi analisado de forma abstracta e reproduzido em equivalentes visuais (feito conseguido pelos semitas e mais eficazmente pelos gregos).

Houve, no entanto dois acontecimentos, no Ocidente, que, segundo Ong, marcaram a interacção da escrita e da oralidade: o desenvolvimento da retórica nas academias e o Latim aprendido como língua morta.

A retórica grega representava o antigo universo da oralidade e a sua tradição filosófica a nova estrutura do pensamento, advinda da caligrafia. Esta arte, embora dissesse respeito ao discurso oral, não deixava de ser um produto da escrita, dadas as regras e a organização científica a que estava sujeita. De facto, sem o aparecimento da escrita, a retórica nunca teria sido tão reflectidamente preparada e tão considerada como foi.

Tal como a retórica, o ensino do latim foi um efeito directo do surgimento da escrita.

Acontece que, ao longo do tempo, o latim foi-se dispersando em várias línguas europeias e a linguagem falada afastou-se muito das suas origens. Contudo, à falta de alternativa, o latim continuou a usar-se no ensino das escolas, na Igreja e nos documentos de Estado. Por seu lado, a Europa continuava uma mistura de centenas de línguas e dialectos, alguns deles nunca escritos até hoje, sendo que o latim era a única língua utilizada na comunicação escrita (outro aspecto em comum com a retórica, em que, para além da sua proveniência clássica, a aprendizagem era maioritariamente masculina).

O latim relacionou-se assim, de forma paradoxal, com a oralidade e a escrita. Por um lado, tornou-se uma língua controlada pela caligrafia. E aqueles que nos séculos seguintes continuaram a falar latim eram também capazes de o escrever, embora já não fossem utilizadores puros da linguagem oral. Por outro, a textualidade, que manteve o latim ligado à sua antiguidade clássica, manteve-o também ligado à oralidade, já que na ideia clássica de educação, preparava-se o orador e não o escritor. 
$\mathrm{Na}$ opinião de Walter Ong, o latim foi um exemplo do poder da escrita para isolar o discurso e um exemplo da produtividade, sem precedentes, desse mesmo isolamento. O latim contribuiu para a objectividade, por ser um meio para estabelecer o conhecimento de forma separada da carga emocional e profunda de uma língua materna. $\mathrm{O}$ latim reduziu as interferências da vida mundana, abrindo caminho ao mundo abstracto da Escolástica medieval e da moderna ciência matemática que se lhe seguiu.

Hoje, as línguas usadas na aprendizagem do discurso são também línguas maternas, o que Ong considera ser uma prova de como a escrita está a perder o seu poder inicial (embora não a sua importância), por força do desaparecimento (ou falta de uso) da língua controlada pela escrita.

Quanto à retórica, esta transitou inevitavelmente da oralidade para a escrita e as suas competências oratórias foram aplicadas à escrita. Gradualmente, a retórica deixou de ser ensinada na sua forma tradicional, omitindo-se mesmo partes relacionadas com o treino do discurso oral. A educação deixou de ser um processo fundamentalmente retórico e ler, escrever e contar passaram a ser representações da educação não retórica, mais ligada aos livros, mais comercial e mais doméstica.

A imprensa veio dar o último impulso à dominância da escrita. Segundo Walter Ong, esta proporcionou a submissão da palavra a um processo maquínico, tornando o seu uso mais cómodo e generalizado. Ong considera, apesar das opiniões de muitos semióticos estruturalistas, que não foi a escrita, mas sim a imprensa que reificou a palavra e com ela toda a actividade intelectual.

A imprensa fez deslocar a dominância do sentido auditivo para a visão, para o espaço visual, e veio determinar a posição das palavras nesse espaço. Ong considera que na imprensa tudo é controlo de posições e a partir do seu surgimento a palavra adquiriu uma colocação definitiva no espaço. A imprensa reforçou o sentido da linguagem, como sendo essencialmente textual. Além disso, produziu um forte impacto no desenvolvimento do sentido de privacidade individualizada, que marca hoje a sociedade moderna.

A imprensa estimulou ainda um certo sentido de clausura, isto é, um sentimento de que aquilo que está impresso está terminado, está encerrado, atingiu um estado completo, além de sugerir que detém um conteúdo próprio, uma vez que visual e fisicamente as páginas impressas têm todas a mesma consistência.

Na era contemporânea do pós-impresso, a transformação electrónica da expressão verbal aprofundou tanto o compromisso da palavra com a escrita (intensificada pela imprensa), como trouxe à consciência a nova era da "oralidade secundária".

Ong considera que os meios electrónicos vieram reforçar os meios de impressão anteriores, mas introduzem um estilo informal auto-consciente.

A forma de processar a palavra no espaço está a ser intensificada com o computador, que maximiza o compromisso da palavra com o espaço, ao tornar o virtual instantâneo.

A nova oralidade aproxima-se da antiga oralidade primária, em questões como a participação mística, a promoção do desenvolvimento do senso comum, o sentido de grupo, a concentração no momento presente. Mas é essencialmente uma xoralidade 
deliberada e auto-consciente, baseada permanentemente no uso da escrita e da impressão.

A aproximação à oralidade primária é evidente, mas também são abismais os aspectos que as separam. De facto, a segunda oralidade depende da existência prévia da escrita. O contraste entre a oratória de hoje e a do passado é bem exemplificativa desta constatação. A rádio e a televisão trouxeram, a um público alargado, figuras cuja participação política não seria possível sem os modernos desenvolvimentos electrónicos.

A oralidade primária fez-se sentir num estilo aditivo, redundante, cuidadosamente equilibrado, dialéctico e numa inter-relação intensa do orador e da audiência. Hoje em dia, os debates, principalmente políticos, estão afastados deste universo da oralidade antiga. A audiência é invisível e inaudível, os oradores fazem pequenas apỉesentações, engatando em conversas curtas com outros, mas sem qualquer ponto de friç̧ão, que, caso exista, é mantido deliberadamente desinteressante. Os media electrónicos não toleram uma exposição antagónica aberta e, apesar do ar de espontaneidade trabalhada, estes são totalmente dominados pela clausura, pelo fechamento, heranças da imprensa, que qualquer sinal de hostilidade poderia quebrar, desmoronando o controlo apertado. Os oradores acomodaram-se à psicologia dos media, que é o mesmo que dizer à psicologia da escrita.

O paradoxo da comunicação humana é que esta é inter-subjectiva, enquanto o modelo de comunicação dos media tende a ser precisamente o contrário. Comunicar implica uma relação entre sujeitos e os media eliminam estas relações.

Walter Ong foi, sem dúvida, brilhante nas suas conclusões, apresentando um caminho para compreendermos como a tecnologia, neste caso da escrita, proporcionou modificações sociais e culturais e como contribuiu para o desenvolvimento cognitivo humano. Acreditamos, porém, que da óptica dos efeitos da tecnologia, principalmente a partir do surgimento dos meios electrónicos, o seu pensamento poderia ter-se desenvolvido em torno de questões suplementares, como a abordagem das influências dos meios electrónicos no corpo, que remetem para uma nova era da comunicação, a era da realidade virtual, na qual se ultrapassam as limitações dos meios e onde de facto a comunicação será novamente intersubjectiva.

\section{Bibliografíia}

Arquivo Digital da Universidade de Saint Louis http://www.slu.edu/readstory/newlink/2974

Ong, W. J. (1999). Orality and Literacy - The Technologizing of the Word, London: Routledge. 